\title{
Anaximandro, a teleologia e a história
}

\section{Anaximander, the teleology and the history}

\author{
FELIPE LUIZ
}

\begin{abstract}
Resumo: O objetivo do presente estudo é elaborar algumas reflexões sobre o pensamento de um dos filósofos pré-socráticos, Anaximandro de Mileto. De maneira geral, entende-se Anaximandro à moda aristotélica, como tendo pensado a arkhé da physis, dando-lhe como fundamento o apeíron. Nosso estudo, em particular, aborda o pensamento de Anaximandro naquilo que consideramos uma asserção sobre o fundamento do ser e seu desenrolar na história em um marco teleológico. Para tanto, lançamos mão dos fragmentos do próprio autor, da doxografia antiga, dos comentários de alguns filósofos contemporâneos, e elaboramos breves comparações com o pensamento teleológico de Hegel; e ademais com autores de vertente marxista, cujo pensamento mantém laços com o de Hegel.
\end{abstract}

Palavras-chave: Anaximandro de Mileto. Teleologia. Teoria da história.

Abstract: Our objective in this paper is to introduce some reflexions about one of the first philosopher Anaximander of Miletus. His thought remains nowadays in a fragment and in the doxography. Generally he is introduced as a philosopher of the arkhé of the physis, who gives the apeiron as fundament. For us, the propositions of Anaximander will be taken as propositions of Philosophy's History, and, particularly, as referring to the fundament of the being and its demarche in the history according to a telos. Aiming these, we have analyzed Anaximander's fragment and also the old doxography and the interpretations of contemporaneous philosophers. Finally, we try to compare Anaximander with the teleological propositions of Hegel and with some Marxists authors.

Keywords: Anaximander of Miletus. Teleology. History theory.

\section{Introdução: o problema da interpretação dos filósofos antigos}

O texto que segue faz parte de uma pesquisa que visa aclarar a possibilidade de uma compreensão da filosofia enquanto uma estratégia. Nestes marcos, retornamos aos primeiros filósofos para ver o que eles têm a nos dizer sobre esta via. Para tanto, analisaremos o pensamento de Anaximandro de Mileto, que deve ser incluído no rol dos filósofos ditos pré-socráticos, aqueles que escreveram antes da aparição da figura cimeira que foi Sócrates e dos grandes sistemas filosóficos que são o de Platão e o de Aristóteles. Anaximandro foi um dos primeiros filósofos, contemporâneo de Tales, ademais oriundo da mesma cidade que este, incluído na chamada Escola Jônica, e, como sói ocorrer com os pensadores desta estirpe, teve múltiplos interesses, que compreendiam não só a especulação e produção filosófica como aqueles temas que hoje consideraríamos adequados mais às ciências naturais que à

\footnotetext{
${ }^{1}$ Bacharel em Filosofia na FFC-UNESP/Marília; licenciando nesta mesma universidade. Foi bolsista PIBIC-CNPQ atuando no tema Filosofia Francesa Contemporânea (Michel Foucault) e epistemologia política da psiquiatria. Posteriormente, dedicou-se a estudar as relações entre o pensamento de Foucault e o anarquismo. Atualmente, estuda as vicissitudes da noção de "filosofia da guerra", com ênfase em Filosofia Antiga. E-mail: gumapoldo51@yahoo.com.br.
} 
filosofia ela mesma. Deve-se distingui-lo de outro Anaximandro de Mileto, que teria sido um historiador versado no jônico (DIÓGENES LAÉRCIO, s/d/, p. 87). O nosso Anaximandro teria escrito três livros, um dos quais chamado Peri physeós, normalmente vertido como Sobre a natureza, tradução polêmica, como mostraremos; e, ademais, o título Sobre a natureza era um tal que tardiamente deuse às obras de "todos aqueles que Aristóteles interpretou como physikoi [físicos], isto é, quase todos os pré-socráticos" (KIRK et ali, 2005, p. 101) os quais teriam escrito sobre a physis.

A compreensão de seu pensamento impõe consideráveis dificuldades ao leitor contemporâneo, dentre as quais destacamos: a necessária leitura em grego arcaico, a fim de evitar a polissemia que as traduções impõem; contudo, o fato de variados vocábulos do grego arcaico terem sofrido mudanças consideráveis, e deixarem em aberto seu sentido, de modo que interpretações díspares podem devir (o que a tradução mascara), deve ser considerado; e o problema da ausência de bibliografia direta, elemento este altamente potenciado no pensamento de Anaximandro, do qual só nos resta uma única sentença tida como direta, e mesmo isto envolto em uma problemática da autenticidade ou falsidade de determinados termos e do fragmento ele mesmo (KIRK et ali, 2005). O último ponto deve ser ressaltado: variada bibliografia relata o pensamento de Anaximandro, mas esta mesma bibliografia tece considerações diferentes, sobre as quais os especialistas hodiernos se debruçam para avaliar o que ele em fato pensava.

Ademais, a maior parte da doxografia de Anaximandro foi empreendida por filósofos que o sucederam em séculos, e um dos mais privilegiados comentadores, Aristóteles, dista cerca de dois séculos de sua vida. A isto se acrescenta as mudanças semânticas que qualquer idioma passa, e o fato da inexistência das modernas preocupações editoriais. Destas considerações, pode-se ter uma idéia do problema envolto na intelecção destas filosofias ditas pré-socráticas, as quais são, por vezes, e injustamente marginalizadas, com, talvez, as notáveis exceções de Parmênides e de Heráclito. Consideramos que há uma atividade filosófica importante nestes pensadores, inclusive em Anaximandro. Desta feita, assumiremos a sentença que nos resta como direta, observando algumas restrições apontadas pelos doutos (KIRK et. ali, 2005, p. 117-18).

\section{O fragmento de Anaximandro e os comentários antigos}

A sentença de Anaximandro, recolhida por Simplício a partir de outras fontes (não do livro de Anaximandro, portanto), é a seguinte:

“...heteran tina physin ápeiron, ex ès ápantas gínesthais toùs ouranoùs kaì toùs en autois kósmous. èx ón dè è génesis esti tois ousi, kai tēn phthoran eis tauta ginesthai katà tò khreōn. didónai gàr autà 
díkēn kai tísin allēlois tēs adikías katà tēn tou khrónou táxin" (SIMPLÍCIO apud KIRK et ali, 2005, p. 117).

Há variadas traduções possíveis. Não seguiremos a de Nietzsche (1973) nem a de Heidegger (1973), sobre a qual tornaremos; elas são incompletas. A de Kirk ${ }^{2}$ et ali é a seguinte:

“...uma outra natureza apeiron, de que provêm todos os céus e mundos neles contidos, $\mathrm{E}$ a fonte da geração das coisas que existem é aquela em que a destruição também se verifica segundo a necessidade; pois pagam castigo e retribuição umas às outras, pela sua injustiça, de acordo com o decreto do tempo" (KIRK et ali, 2005, p. 117).

Não discutiremos no que consiste o apeiron; normalmente é traduzido como indefinido ou como indeterminado; apontaremos que em sua composição encontrase o privativo $a$ e a raiz peira, experiência e também limite. Utilizaremos o termo no original grego. A discussão sobre o estatuto do apeiron é longa e técnica, implicando debater em profundidade ${ }^{3}$ a bibliografia antiga acerca do tema; esta questão faz lembrar Porfírio no Isagoge (PORPHYRIUS, 1947): se o apeiron é substrato das coisas ou só seu princípio? Se ele existe diferentemente delas ou com elas? Assim, para Aristóteles, ele indica o espacialmente infinito; para Conford, é "aquilo que é internamente ilimitado, sem distinções internas" (KIRK et ali, 2005, p. 109). Em todo caso, Anaximandro tomava que a substância constitutiva do mundo era diferente dos elementos já formados.

O problema acerca de sobre o que Anaximandro está tratando é denso; daremos nossa própria interpretação adiante, antes discutindo a interpretação do pensamento de Anaximandro com os antigos e os modernos. Sinteticamente, ele aborda "as coisas" (ousi, ón), e utiliza o vocábulo physin, acusativo de physis, traduzido como "da natureza". Elas provêm (ginesthais) do apeiron, e para ele retornarão em sua destruição (pthoran), existindo na ordem ou segundo a sentença (táxin) do tempo, e nele reciprocamente dando-se justiça (diké) e castigo (tisin) pelas injustiças (adikiás), segundo a necessidade (to khreón). Podemos chamar a interpretação dominante da sentença de Anaximandro de fisicista; esta interpretação segue sobremaneira Aristóteles, mas também outros filósofos antigos, para os quais Anaximandro estaria querendo determinar a natureza da natureza e de como as coisas devêm nela; ela apóia-se na filologia dos termos da sentença, e se podem encontrar trabalhos de interpretação da sentença nestes marcos ${ }^{4}$.

\footnotetext{
${ }^{2}$ O livro de Kirk et ali foi traduzido por Carlos Alberto Mouro Fonseca.

${ }^{3}$ PRATES E SILVA (1992) faz esta discussão. Em síntese, Prates reconstrói filologicamente o livro de Anaximandro a partir da doxografia e dos trabalhos dos especialistas modernos, como Kahn, Gigon e Heidel. Seu trabalho está nas entrelinhas do nosso, posto que ensaiamos uma outra interpretação, não fisicista, mas respeitamos e utilizamos elementos de sua empreitada.

${ }^{4}$ Por exemplo, PRATES E SILVA, 1992.
} 
De fato, na Metafisica, Aristóteles, ao comentar os filósofos que o precederam , considera de maneira geral que estes não abordaram concomitantemente as quatro causas que ele expõe, tendo alguns, antes, se apegado a somente uma delas e outros a mais do que uma; mas nunca as quatro simultaneamente. Para ele, os primeiros filósofos concebiam o primeiro princípio enquanto corpóreo, uns tomando-o como uno, e outros como múltiplo; eles teriam tentando definir o quê (ti estin, quiditas, quididade) das coisas de forma rudimentar (ARISTÓTELES, 983a-987a). Aristóteles não cita nominalmente Anaximandro, mas Tales; o comentário aristotélico sobre Anaximandro ocorreu, sobretudo, em outros escritos, como na Física e na Meteorologias (BARNES, 2003; KIRK et ali, 2005; SOUZA et ali, 1978), sendo que, na Metafísica, este comentário é colateral . Na Física, ele comenta o apeiron e o discute em variados termos; na Metereologia, ele debate as noções cosmogônicas de Anaximandro. De todo modo, deu Anaximandro como um dos filósofos que pensaram a arkhé da physis tomando-a como o apeiron; adiciona-se também o que teriam sido suas concepções cosmogônicas, zoogênicas e antropogênicas. Aristóteles parece não ter comentado, propriamente, o fragmento que nos restou, embora ele talvez tenha tido acesso aos livros completos de Anaximandro.

A interpretação de que Anaximandro estaria tratando da physis, entendida como natureza, e de que suas preocupações seriam dessa ordem é, ademais, reforçada por outros intérpretes antigos, como Simplício, Teofrasto, Hipólito, Plutarco, Censorino, dentre outros (apud BARNES, 2003). Ademais se some a isto que a doxografia nos lega que Anaximandro elaborou um mapa (foi o primeiro a fazê-lo, ao que nossa bibliografia indica) e colocou um relógio de sol em Esparta. Suas considerações de ordem zoogênica e antropogênica reforçam esta interpretação e, de mais a mais, foi ele contemporâneo de Tales, que deu o como elemento (stokeion), substrato (upokeímenon) ou princípio (arkhé) das coisas a água.

Esta interpretação fisicista não se restringe aos antigos. Em autores contemporâneos, encontramos o mesmo gênero de raciocínio. Cresson (1960) afirma que os filósofos da Escola Jônica teriam buscado explicar o mundo físico, o mundo intelectual e o mundo moral a partir da observação dos elementos da natureza, valendo-se, ademais, de sua imaginação; nestes termos, Anaximandro teria partido do infinito indeterminado o qual teria gerado tudo por separação. Por sua vez Barnes (2003), interpreta, seguindo alguns autores antigos, que, por exemplo, as injustiças que as coisas se pagam umas às outras (conferir a sentença acima) seriam referências, por exemplo, à alternância entre frio e calor ou inverno e verão, de modo mesmo que uma especulação propriamente ontológica não teria tido lugar em Anaximandro, mas outra cosmogônica.

Quer dizer, as preocupações de Anaximandro seriam da ordem do que hoje chamaríamos de ciências naturais, implicando, assim, que seu pensamento pouco 
teria a contribuir com o pensamento filosófico atual; o interesse que poderíamos encontrar nele é da ordem da erudição ou, no melhor dos casos, como um precursor das modernas teorias científicas e geográficas. Discordamos desta concepção, e tentaremos argumentar a respeito. Observamos com Beaufret, malgrado algumas reservas, que "a essência da filosofia poderia bem ser sua própria história e que tal história poderia bem constituir por sua vez o elemento o mais interior da história universal" (BEAUFRET, 1955, p. 3; a tradução é nossa). Para nós, Anaximandro faz parte desta história e deve ser pensado como filósofo.

\section{A doxografia moderna: Hegel, Nietzsche, Heidegger}

Há diferenças entre a doxografia moderna e a antiga no que tange à interpretação de Anaximandro. Analisaremos três posições diferentes, cada qual sui generis. Antes uma nota. Beaufret (1955) aponta que a preocupação com a história da filosofia é recente, e que, exempli gratia, Kant tinha um conhecimento débil da mesma. De fato, há uma retomada dos pré-socráticos desde o século XVI, com as edições de Stephanus; note-se que Hume escreveu uma história da Inglaterra e que Kant elaborou seu famoso opúsculo sobre a história. Há outros pensadores que se debruçaram sobre o problema particular da história; mas parece ser com Hegel que temos uma concepção na qual a história em geral, e a história da filosofia em particular, é central para o próprio conhecimento filosófico.

Observamos que, em variados textos de Hegel, a noção de historicidade desempenha papel nodal; e inclusive certas opções de seu vocabulário, por exemplo momento, preferencialmente a termo menor ou termo médio ou premissas, dão mostras da centralidade da questão da sucessão temporal em sua reflexão. Encontramo-la na Fenomenologia do Espírito e também em outros escritos; tonaremos a este ponto.

Anaximandro é, nestes marcos historicizantes, entendido por Hegel em termos de sucessão e predecessão, no desenrolar da autocompreensão do absoluto. Hegel considera-o em referência a Tales e a Anaxímenes, sobretudo, e o toma como um pensador limitado, que deu o apeiron como fundamento e finalidade; de passagem, Hegel aponta que Aristóteles considerava o apeiron enquanto potência (dunámei) real. Citando Eusébio, Hegel trabalha com as concepções cosmogônicas de Anaximandro, segundo a qual do apeiron mundos infinitos teriam devindo e também ruiriam, porque existem em se eliminando. Hegel endossa a opinião de Aristóteles sobre os problemas destas filosofias e considera que os jônicos "possuem pobres pensamentos abstratos"5 (HEGEL, 1966, p. 176).

Para Hegel, o pensamento dos jônicos teria passado por três fases. A primeira seria a afirmação da essência como água. A segunda seria o pensamento de

\footnotetext{
${ }^{5} \mathrm{~A}$ tradução é nossa.
} 
Anaximandro e a asserção do infinito enquanto descrição do movimento segundo a forma da condensação e da dissolução. A última seria a asserção do ar (pneuma), que Hegel compara ao espírito (pneuma), ou seja, Anaxímenes, o qual teria preparado a transição à filosofia de Pitágoras na qual o pensamento se desprende do sensível e, disto, se desfaz também da separação entre inteligível e real, etc (HEGEL, 1966).

Nietzsche (1973) destoa das concepções prévias, posto que pensa que a interpretação do indeterminado não deve ser feita fisicamente, como toda a tradição parece ter feito até então; para ele, o apeiron não deve ser entendido fisicamente, mas em um sentido ético. Nietzsche considera que a questão fundamental de Anaximandro era entender o sentido da existência em um mundo que se renova. Diante da unidade, Anaximandro teria se perguntado pela multiplicidade, dando como resposta o caráter contraditório do que se faz e se consome, de modo que a existência se torna um fenômeno moral que se penitencia por existir.

No contexto de sua recuperação dos pré-socráticos a fim de mostrar o processo de esquecimento do ser desencadeado pela metafísica, nos marcos da distinção ôntico-ontológica (ESTIÚ, 1959), é que Heidegger aborda Anaximandro à moda genealógica e termina por refazer mesmo toda a sentença. Para Heidegger, Anaximandro deve ser inscrito na escatologia do ser, o qual se dá termos de recolhimento (légesthai, lógos), posto que o filósofo da Floresta Negra tenta elaborar, como Hegel, uma história da filosofia que filosofe. "A sentença [de Anaximandro] fala do ente múltiplo em sua totalidade" (HEIDEGGER, 1973, p. 24); ele inclui as coisas da natureza, mas também as humanas, as divinas e as demoníacas, de modo que a concepção aristotélica de que se trata de meramente coisas naturais não se sustentaria; de modo mesmo que não se pode sustentar que Anaximandro teria antropomorfizado a natureza com sua terminologia.

Para Heidegger a compreensão do que significou Anaximandro com sua sentença necessariamente deve abrir mão, por exemplo, de uma linguagem conceitual, a qual está baseada na noção do ser enquanto representado, enquanto idea, noções platônicas e aristotélicas, assim como as noções de génesis e phthorá, também próprias a um tipo de pensamento posterior aos pré-socráticos. Debruçando-se sobre o sentido original da sentença grega, Heidegger termina por traduzi-la como "segundo a mantença deixam por ter lugar o acordo e assim também o cuidado, um para o outro (no penetrar e assumir) do desa-acordo" (HEIDEGGER, 1973, p. 47); e acrescenta que sua tradução não é científica, id est, não segue os parâmetros filológicos tradicionais; de fato, ela é acorde com a concepção histórico-filosófica do segundo Heidegger (ESTIÚ, 1959). É particularmente difícil debater a tradução heideggeriana nestes termos, posto que ela implica uma concepção sui generis de determinados vocábulos, muita além daquela propriamente lexical. De todo modo, não a seguimos e assumimos o fragmento 
transmitido por Simplício na íntegra como de Anaximandro e, embora acordemos com outros elementos genealógicos de Heidegger, nos damos o direito de ensaiar uma interpretação particular da sentença do milésio, discordando de Heidegger ${ }^{6}$.

\section{A teleologia de Anaximandro e o problema da arkhé e da physis}

Trataremos, primeiramente, dos problemas relativos à tradução de determinados termos. É consenso que Anaximandro introduziu o conceito de arkhé. Simplício: “arkhēn te kaí stokheion eírēke tōn óntōn tò apeiron prōtos tounoma kalesas tēs archēs" (apud KIRK et ali, 2005, p. 106); em tradução livre, "disse a arkhé e os elementos do ser o apeiron, primeiramente o nome arkhé tendo introduzido". Já apontamos que um dos grandes recuperadores dos pré-socráticos foi Hegel, e isto pode ser dito, em geral, em relação aos alemães. Vertido para o alemão, arkhé foi traduzido como Anfang ou fang an, "início”, "começo", "ponto de partida” ou como Prinzip, "princípio”, “norma” (DIELS, KRANZ, 1959, p. 75); e o verbo arkhein como beginnem (idem, p. 74). Diels e Kranz dão ademais outros sentidos de arkhé, como "aquilo que é anterior" e "origem". Contudo, o verbo arkhein guarda múltiplos sentidos, especialmente "começar", "principiar", mas também "guiar”, “comandar", "ser o chefe", "submeter". E os demais sentidos e derivados de arkhé são ainda mais reveladores, posto que significa também "comando", "poder", "autoridade"; e também "império", “reinado”, “governo"; e dele deriva arkhaí, “autoridade”, "magistrado". O verbo na primeira pessoa do indicativo singular, arkhó, indica a ação de "ser o primeiro", de "prevalecer", de "dominar", de "comandar algo ou alguém”. Percebe-se que no alemão $^{7}$, e em outras línguas, dentre as quais o português, a pletora de significados é perdida e a interpretação é encaminhada a uma via determinada.

A tradução de physis por "natureza” tem que ser problematizada também. Aristóteles distinguiu sete sentidos de physis "acabando por se fixar em sua acepção como a essência das coisas que possuem uma fonte de movimento própria" (BLACKBURN, 1997, p. 150). Vê-se, pois, que se trata de algo especialmente distinto da noção hodierna de "natureza", tanto mais que, na modernidade, com o desenvolvimento da ecologia e das ciências naturais, temos uma concepção certamente distinta daquela antiga sobre o que viria a ser natureza. Ademais, o verbo phyein significa "impelir", "fazer nascer", "fazer crescer". Elaborando a genealogia do termo, Heidegger considera que a tradução latina de physis por natura ressignificou o conceito; ele designaria antes, o "ser mesmo pelo qual o ente devêm e se sustêm"; ela é "aquilo que tem vigência”; este seria seu sentido nos pré-

${ }^{6}$ PRATES E SILVA (1992), em estudo de tradição fisicista, como ora chamamos, comenta Heidegger em uma nota de rodapé, para que se tome consciência da pouca importância que os especialistas na temática dão à interpretação heideggeriana.

${ }^{7}$ Em alemão Anfang liga-se ao verbo fangen, que significa "apanhar", "flagrar". A etimologia é reveladora neste como em outros casos. 
socráticos. Posteriormente, ainda na antiguidade, identificou-se-lhe com tá physei onta, "os entes naturais", e se opunha a physis a thésis, "posição", "estatuto", ao nomos, "lei", "costume", e a technē, cujo sentido exato está entre técnica e arte (como a arte do ourives, exempli gratia) (HEIDEGGER, 1969) ${ }^{8}$.

Aristóteles teria compreendido os filósofos anteriores a si nos marcos de sua Física e interpretado os phýsei onta em oposição aos téchné onta, "os primeiros sendo aquilo que no seu emergir-se produzem a partir de si mesmos; os outros são aquilo que é produzido através de representação humana" (HEIDEGGER, 1973, p. 21). E desde então, passando por Teofrasto (no qual surge a tradição doxográfica) e Simplício (que recolhe de Teofrasto a sentença que apresentamos como citação direta), dentre outros, cristalizou-se a tradição de interpretar os pré-socráticos enquanto pré-socráticos e que suas investigações seriam acerca da natureza da natureza, ademais, inferiores ou insuficientes às de Platão ou Aristóteles. Isto tudo mais de mil anos depois da morte de Anaximandro.

Vê-se, pois, que apesar de Anaximandro ter preocupações naturalistas, sua reflexão não pode ser contida nestes marcos, e há uma história precisa desta interpretação, a qual esboçamos. A investigação do milésio é mais ampla; diz respeito ao desenrolar do ente na história a partir do fundamento do ser. Se a tomarmos restritamente, como quer a tradição, ela abordaria tão somente os entes naturais; esta interpretação de physis como natureza desde os pré-socráticos implicaria, pois, por exemplo, no caso de Heráclito, segundo a proposição 53, que as coisas naturais são fruto da guerra, mas não as humanas, distintas da physis, posto que Heráclito diz "pólemos pantón mèn patér estí", "de todas as coisas pai a guerra é" (DK 53 in BERGE, 1969, p. 260-1); esta interpretação é absurda, como se vê. Do mesmo modo, a referência de Anaximandro a um vocabulário jurídico (diké, adikía, taxis) certamente deve ser ligada a uma noção mais ampla de arkhé; estranhamente, Heidegger nem Nietzsche nem Hegel polemizam com a redução de significado do vocábulo, embora Nietzsche saliente a necessidade de uma interpretação ética. Exempli gratia, "a palavra taxís sugere uma sentença de castigo proferida pelo juiz, ou mais propriamente, a imposição de um tributo como nas listas de tributo atenienses (KIRK et ali., 2005, p. 120). Há, por fim, que salientar, que Anaximandro não utilizou, provavelmente, o vocábulo physis, mas, sim, kósmos, o qual, derivado do verbo kósmeo, significa "por em bela ordem"; o kósmos é mais amplo que physis, na medida em que compreende não só as coisas ditas naturais, como também as humanas (PRATES E SILVA, 1992).

Que Anaximandro está tratando do desenrolar dos entes, quer dizer, daquilo que surge e se mantém (physis), ou, antes, da bela ordem cósmica (kósmos), a partir de seu fundamento é evidente. Pseudoplutarco: "tò apeiron phanai tēn pásan aitian éxein tēs tou pantos genéseós te kaí phthorás” (apud KIRK et ali, 2005, p. 106); “o

\footnotetext{
${ }^{8}$ Para o problema da técnica, HEIDEGGER, 2006.
} 
apeiron continha a causa total da origem e da destruição". O apeiron é da ordem da arkhé, um princípio que governa, que comanda; de fato, diz Plutarco sobre o apeiron: "esse princípio o contêm todo e todo o governa, e é, segundo ele, o divino, o imortal e o imperecível" (apud HEGEL, p. 171) ${ }^{9}$. Seu governo é da ordem da necessidade, impõe-se como necessário, e esta imposição implica que as coisas reciprocamente se relacionem segundo a justiça e a injustiça que se dão umas às outras. A existência não é, pois, livre, mas condicionada.

Há uma finalidade no mundo, tal seja, a destruição. Pode-se ter que a destruição, como ademais a gênese, é necessária, independente da volição de um sujeito, ou de seus anseios. O todo de um ente em específico, e o todo em geral, dáse em uma ordem que escapa às questões individuais; já se disse, mesmo, que o traço característico da filosofia grega é ser uma filosofia da necessidade. Hipólito afirma que Anaximandro légei dè khrónon, "fala do tempo". É fato, esta existência das coisas desenvolve-se na temporalidade. Anaximandro elabora, portanto, um discurso (lógos) sobre o primeiro (prótos, arkhé) e o último (éskhatos), sobre o que está na extremidade: as coisas necessariamente, se geradas, são destruídas; elas vieram do apeiron e para ele retornarão; têm um tempo de vida, de duração. Há, como se vê, um discurso certamente físico, mas um que escapa a mera questão física, na medida em que ele se refere ao tempo, a existência das coisas no tempo, inclusive as humanas.

Chama-se filosofia da história aquela disciplina que debate as causas do movimento histórico e do progresso do gênero humano (PLHEKANOV, 1974, p. 9). A concepção escatológica de Anaximandro deve, portanto, ser tomada como o primeiro discurso não religioso sobre o desenrolar dos fatos na história. A causa do movimento histórico, quer dizer, a geração das coisas, inclusive as humanas, é o apeiron, e seu destino, seu telos é também o apeiron. De fato, para Plekhanov, as primeiras filosofias da história tem acentuado caráter teológico, e debate-se mesmo se o apeiron possui ou não caráter divino. A concepção teológica da história foi desenvolvida, dentre outros, por Agostinho e por Bossuet; Agostinho "encara os acontecimentos históricos como submetidos à providência divina e está convencido de que eles não podem ser encarados de outra maneira" (idem, p. 11); Bossuet pensava que a providência divina guiava as ações dos povos, cuja finalidade era o bem do cristianismo. Retornando a Anaximandro, afirmamos com Kirk et ali que

"É possível que o domínio exercido [pelo apeiron] sobre todas as coisas se verificasse através da lei de retribuição entre os contrários, lei ou (modo de comportamento) que teve início quando as primeiras substâncias opostas apareceram no indefinido e que ainda dirige todas as transformações do mundo" (KIRK et ali, 2005, p. 116).

\footnotetext{
${ }^{9}$ A tradução é nossa.
} 
E acrescentamos, para o qual o mundo se dirige. Nesta escatologia ontológica, há a possibilidade do mundo. Do apeiron vieste e ao apeiron retornarás; ele domina (archei) as coisas, na medida em que as engendra. Todas as coisas, inclusive as humanas, pagando-se justiça e castigos pelas injustiças, necessariamente, na ordem do tempo. Nietzsche disse: "imprimir ao devir o caráter de ser - eis a suprema vontade de poder" (apud HEIDEGGER, 1973, p. 25); não se trata, portanto, de um recolhimento ${ }^{10}$, como quer Heidegger, uma concepção ademais necessária às suas teorias, segundo a qual haveria uma distinção entre os primeiros filósofos e o que se seguiu em uma grade de esquecimento do ser em benefício do ente (HEIDEGGER, 1983); Anaximandro formulou um princípio (arkhé) que domina (archei) não um ente em particular, como a techné do sapateiro, mas o ser, o ser ele mesmo: dominar, eis o objetivo dos primeiros filósofos.

\section{Algumas teleologias hodiernas}

A concepção teleológica da história fez carreira. Encontramo-la nos autores cristãos e também no cristianismo popular, como os famosos episódios milenaristas na Europa. Pode-se supô-lo em variados episódios na história ocidental. Contudo, em termos filosóficos, afora Agostinho e Bossuet, citamos de passagem Scheling, para quem a "evolução histórica é uma sucessão de fenômenos submetidos à leis" (PLEKHANOV, 1974, p. 24). São muitas as concepções teleológicas contemporâneas, como é o caso de Comte; iremos nos ater sobretudo a Hegel e pontuaremos este problema no marxismo.

Plekhanov resume Hegel; para este (...) "a Historia é apenas o desenvolvimento do Espírito universal no tempo. A filosofia da História é a História considerada como inteligência" (idem, p.24). De fato em Hegel (1983) encontramos uma definição da história da filosofia voltada a um fim, o conhecimento do absoluto, ademais compartilhado com a religião; por outro lado, no que tange aos procedimentos, a filosofia teria a ver com a ciência. Para Hegel, portanto, as distintas filosofias devem ser compreendidas enquanto momentos da compreensão do absoluto, momentos estes necessários, na medida em que as colocações de um são retomadas pelo filósofo seguinte em um grau mais elevado. Por exemplo, em Anaximandro encontramos a formulação do princípio como apeiron, em Anaxímenes este princípio já se expressa sob a forma dúbia do pneuma (sopro, ar, mas também espírito), em Pitágoras desprende-se do mundo sensível, etc. (HEGEL 1996).

Esta concepção também está expressa, exempli gratia, na Fenomenologia do Espírito; se as formas da consciência se sucedem, uma parte da outra para suprassumí-la em um nível mais elevado: o entendimento e o problema da coisa

\footnotetext{
${ }^{10}$ Um dos sentidos de legein, aparentado ao logos, é, precisamente, recolher. Mas seu sentido mais forte é dizer, falar.
} 
enquanto força pressupõe que o entendimento já tenha elevado o meramente sensível do isto e do aqui ao nível do universal. Do mesmo modo, quanto à disputa entre o senhor e o escravo, pressupõe-se que a consciência já se tenha elevado ao nível da consciência-de-si; e também a consciência infeliz implica a luta entre o senhor e o escravo. As formas de consciência se sucedem, mas em uma via da necessidade. Pode-se bem debater se necessidade no sentido que teve de ser assim (id est, ocorreu deste modo) ou se necessidade em um sentido de dever-ser (porque tinha de ser assim em todos os casos); não temos resposta precisa a esta questão, embora tendamos a afirmar que a interpretação a mais correta é no sentido do dever-ser, posto que a analogia que Hegel empreende é com a flor, que está contida na semente: da semente necessariamente advêm a flor, salvo interrupções externas (HEGEL, 1992).

Concluiremos nossa reflexão pontuando outra polêmica, a de saber se no marxismo, sabidamente tributário da filosofia teleológica de Hegel, estas concepções seguem em vigência. Plekhanov afirma que não. Segundo ele, "a ideia fundamental de Marx se reduz ao seguinte: as relações de produção determinam todas as outras relações (...) na vida social. As relações de produção são determinadas (...) pelo estado das forças produtivas" (PLEKHANOV, 1974, p. 33). A vida social é compreendida em termos de atividade, de onde resultaria a negação de que exista teleologia na história. Os homens, ao produzir sua própria história visando satisfazer suas necessidades, excluem as predestinações históricas, mesmo aquelas do comunismo.

Contudo, para contrapô-lo, utilizaremos ninguém menos que Stálin. Para ele, expondo os fundamentos do que considerava o materialismo histórico-dialético, o desenvolvimento histórico passaria por mudanças quantitativas e qualitativas em saltos bruscos, que não são contingentes, mas necessários. E as "revoluções realizadas pelas classes oprimidas constituem um fenômeno absolutamente natural, inevitável" (STALIN, 1978, p. 22). Ademais, sendo as forças produtivas - grosso modo, os instrumentos de trabalho - as bases das relações em sociedade; e como das mudanças nas forças produtivas seguem-se mudanças sociais; e visto que "o proletariado se servirá da sua supremacia política para arrancar (...) todo capital à burguesia" (idem, p. 53); parece-nos justo afirmar que há certo encaminhamento teleológico na visão de Stálin; de fato, citando Marx, Stálin diz que: "há um movimento contínuo das forças produtivas, de destruição das relações sociais, de formação nas ideias; não há nada mais imutável que a abstração do movimento" (MARX apud STÁLIN, 1978, p. 49). Parece que se o marxismo rompe com a teleologia, esqueceram de avisar a Stálin...

E não só ele. Um Gurvith, comparando as dialéticas de Proudhon e Marx, considera que Marx atribuía destino às classes sociais, como Hegel às nações. Gurvitch considera que (...) "em Marx (...) a dialética continua a ser a marcha da 
humanidade para a salvação definitiva" (GURVITCH, s/d/, p. 104); e arrebata: "graças à dialética histórica, a dialética ascendente de Marx é uma marcha triunfal através das revoluções, para uma humanidade enfim desalienada de todas as servidões e reconciliada consigo próprio" (idem, p. 104); e conclui que em Marx encontra-se uma escatologia (idem, p. 105). A polêmica está lançada. Em todo caso, a problemática de Anaximandro ressoa no presente, ao que parece.

\section{Referências}

ANAXIMANDRO DE MILETO. Doxografia e fragmentos in SOUZA, J. de et ali; Os présocráticos. 2. ed. São Paulo: Abril Cultural, 1973.

ARISTÓTELES. Metafísica. Bauru, SP: Edipro, 2006.

Metafisica I e II. São Paulo: Abril Cultural, 1979.

BAILLY, A. Dictionnaire grec-français. Paris: Hachette, 1950.

BARNES, J. Filósofos pré-socráticos. São Paulo: Martins Fontes, 2003.

BEAUFRET, J. Le poème de Parménide. Paris: PUF, 1955.

BERGE, D. O logos heraclítico. Rio de Janeiro: Instituto Nacional do Livro, 1969.

BLACKBURN, S. Dicionário de filosofia. Rio de Janeiro: Zahar, 1997.

CRESSON, A. A filosofia Antiga. 2. ed. São Paulo: Difusão Européia do Livro, 1960.

DIELS, H.; KRANZ, W. Die fragmente der Vorsokratiker Berlin: Wiedmansche, 1951.

DIOGENES LAÉRCIO. Vidas, opiniones y sentencias de los filósofos más ilustres. Buenos Aires: Emecé, s/d.

ESTIÚ, E. "El problema metafísico en las últimas obras de Heidegger" in HEIDEGGER, M. Introducción a la metafisica. 2. ed. Buenos Aires: Nova, 1959.

GURVITCH, G. Proudhon e Marx II: uma confrontação. Lisboa: Presença, s/d.

HEGEL, G. W. F. Fenomenologia do espírito. Petrópolis, RJ: Vozes, 1992, vol. I. . Introdução à história da filosofia. São Paulo: Hemus, 1983.

. Lecciones sobre la historia de la filosofia México: Fondo de Cultura Economica, 1996.

HEIDEIGGER, M. "A sentença de Anaximandro" in SOUZA, J. de et ali. Os pré-socráticos. 2. ed. São Paulo: Abril Cultural, 1973.

. Carta sobre o humanismo. 3. ed. Lisboa: Guimarães Editores, 1983.

. Ensaios e conferências. 3. ed. Petrópolis, RJ: Vozes/São Francisco, 2006.

. Introdução à metafísica. 2. ed. São Paulo: Tempo Brasileiro, 1969.

Introducción a la metafisica. 2. ed. Buenos Aires: Nova, 1959.

. "Que é metafísica?", in SARTRE, J.P. São Paulo: Abril Cultural, 1973.

KIRK, G. S.; RAVEN, J. E.; SCHONFIELD, M. Os filósofos pré-socráticos. 5. ed. Lisboa:

Calouste Gulbenkian, 2005.

NIETZSCHE, F. "A filosofia na época trágica dos gregos", in SOUZA, J. de et ali. Os présocráticos. 2. ed. São Paulo: Abril Cultural, 1973. 
PLEKHANOV, G. A concepção materialista de história. 4. ed. Rio de Janeiro: Paz e Terra, 1974.

PRATES E SILVA, R. C. B. A justiça cósmica (um estudo sobre Anaximandro de Mileto). Tese de Livre-docência, Araraquara: FCL-UNESP, 1992.

SOUZA, J. C. de et ali. Os pré-socráticos. 2. ed. São Paulo: Abril Cultural, 1973.

STÁLIN, J. O materialismo dialético e o materialismo histórico. São Paulo: Global, 1978.

Submissão: 02.08.2018 / Aceite: 10.09.2018. 